\title{
Mathematical modelling of the action potential of human embryonic stem cell derived cardiomyocytes
}

Michelangelo Paci ${ }^{1 \dagger}$, Laura Sartiani ${ }^{2 \dagger}$, Martina Del Lungo ${ }^{2}$, Marisa Jaconi $^{3}$, Alessandro Mugelli ${ }^{2}$, Elisabetta Cerbai ${ }^{2 \dagger}$ and Stefano Severi ${ }^{{ }^{*}+}$

\footnotetext{
* Correspondence: stefano.severi@ unibo.it

†Equal contributors

${ }^{1}$ Biomedical Engineering Laboratory - D.E.I.S, University of Bologna, Via Venezia 52, Cesena 47521, Italy Full list of author information is available at the end of the article
}

\begin{abstract}
Background: Human embryonic stem cell derived cardiomyocytes (hESC-CMs) hold high potential for basic and applied cardiovascular research. The development of a reliable simulation platform able to mimic the functional properties of hESC-CMs would be of considerable value to perform preliminary test complementing in vitro experimentations.
\end{abstract}

Methods: We developed the first computational model of hESC-CM action potential by integrating our original electrophysiological recordings of transient-outward, funny, and sodium-calcium exchanger currents and data derived from literature on sodium, calcium and potassium currents in hESC-CMs.

Results: The model is able to reproduce basal electrophysiological properties of hESC-CMs at 15-40 days of differentiation (Early stage). Moreover, the model reproduces the modifications occurring through the transition from Early to Late developmental stage (50-110, days of differentiation). After simulated blockade of ionic channels and pumps of the sarcoplasmic reticulum, $\mathrm{Ca}^{2+}$ transient amplitude was decreased by 12\% and 33\% in Early and Late stage, respectively, suggesting a growing contribution of a functional reticulum during maturation. Finally, as a proof of concept, we tested the effects induced by prototypical channel blockers, namely E4031 and nickel, and their qualitative reproduction by the model.

Conclusions: This study provides a novel modelling tool that may serve useful to investigate physiological properties of hESC-CMs.

Keywords: Embryonic stem cells, Computer simulation, Action potential, Pharmacology

\section{Background}

Human Embryonic Stem Cells (hESCs) are pluripotent cells derived from the blastocyst stadium of human embryos, having the potential to differentiate in all the three embryonic germ layers [1]. Many studies have been carried out to identify the most advantageous strategies to drive the differentiation towards the desired cell phenotypes thus allowing valuable investigations in basic research and suggesting useful perspectives for regenerative purposes. In the cardiovascular field, hESCs provide a powerful tool to clarify key developmental steps of cardiac embryogenesis [2], to develop reliable

(c) 2012 Paci et al.; licensee BioMed Central Ltd. This is an Open Access article distributed under the terms of the Creative Commons Attribution License (http://creativecommons.org/licenses/by/2.0), which permits unrestricted use, distribution, and reproduction in any medium, provided the original work is properly cited. 
in vitro models for drug toxicity screening [3] and are considered a promising source for cell-based therapies in pathologies such as myocardial infarction or pace-maker center dysfunction [4]. Studies involving hESCs differentiated toward the cardiac phenotype are rather demanding due to difficulties such as i) low efficiency process of differentiation [5]; ii) dishomogeneity of cell phenotypes; iii) laborious phenotypic characterization, e.g. via patch-clamp or multicellular and multi-electrode array recordings [6-8]. Another complication arises from the observation that hESC-derived cardiomyocytes (hESC-CMs), like fetal cardiomyocytes (CMs), are electrophysiologically immature [6]; their properties evolve during in vitro culturing [6], a phenomenon which appears to be regulated by interactions with non-cardiomyocytes in embryoid bodies (EBs) [9].

To date extensive information is available mostly as unsystematic mass of basic electrophysiological properties of different hESC lines differentiated toward the cardiac lineage and on the modifications occurring during maturation or upon exposure to different drugs or chemicals. Nonetheless, no attempt was done to systematize current knowledge to fully evaluate the impact of individual key ionic currents and of excitation-contraction coupling mechanisms on basic physiology in hESC-CMs [10-13].

Computational modelling represents a consolidated approach in cardiac research to simulate the electrophysiology of single cell or cell-made tissue [14] and the modifications induced by chemicals and drugs. This approach usually complements in vitro and in vivo experimentation to create a compelling tool able to predict physiological responses, abnormal reactions to drug application and to formulate new hypotheses.

The aim of this work is to develop a computational model of action potential (AP) of H1-hESC-CMs allowing to follow the maturation process. Due to the shortage of measurements, especially at advanced developmental stages, this model can help to infer developmental mechanisms not obvious from the bare measurements.

Data on membrane ionic currents for this cell line coming from our original measurements of transient outward potassium, funny, sodium-calcium exchanger currents, and data from literature on sodium, calcium and potassium currents in hESC-CMs were integrated into the model. To take into account the presence of non-cardiac cells in intact EBs, a further model assessment is proposed by coupling the hESC-CM model with modelled fibroblasts and evaluating their impact on the AP. The formulated model simulates i) the main basic AP features and ii) the developmental changes documented during in vitro maturation.

\section{Methods}

Methods for hESC-CM culture, differentiation and electrophysiological recording are described in Additional file 1. hESC-CM were included in the Early or Late group according to differentiation time, i.e. from 15-40 and 50-110 days, respectively [6].

\section{Model of $h E S C-C M A P$ and its transition from Early to Late stage of development}

The starting point in developing the hESC-CM model was a modified version [15] of the TenTusscher model of human adult ventricular CM [16], this parent model was then largely modified by changing the formulation of almost all the currents to incorporate all the available data on hESC-CMs and by adding two currents $\left(\mathrm{I}_{\mathrm{f}}\right.$ and $\left.\mathrm{I}_{\mathrm{CaT}}\right)$ that 
are not present in the adult ventricle. Following the classical Hodgkin-Huxley formulation [17], the cell electrophysiological behaviour is described by Eq. 1:

$$
\frac{d V}{d t}=-\frac{I_{i o n}}{C_{m}}
$$

where $V$ is the membrane potential, $C_{m}$ the membrane capacitance and $I_{i o n}$ the sum of all the membrane currents. Details on each current are in the following subsections.

Properties of ion currents based on our recordings or derived from literature data on hESC-CMs were integrated into the model to reproduce Early and Late hESC-CM APs. Where data from hESC-CMs were not available, observations in ESC-derived or embryonic CMs from different species were considered. Although ionic channels undergo complex regulation at a transcript level, the I/V relationship of most currents does not change among different developmental stages [18-22]. Hence, we assumed that developmental changes in each current, $\mathrm{I}_{\mathrm{xx}}$, are determined mainly by its quantitative change, which can be represented by setting a variable fraction (ratio, $\operatorname{RaI}_{\mathrm{xx}}$ ) of the current maximal conductance in the adult model. Table 1 summarizes the maximal conductance values for the main currents in the model.

\section{Sodium current $\left(I_{\mathrm{Na}}\right)$}

Our $\mathrm{I}_{\mathrm{Na}}$ formulation slightly changes the original adult model (Additional file 1: Eqs. S3, S6 and S8, in Additional file 1). The steady-state inactivation was changed according to Satin et al. data on inactivation dynamics of H9.2-hESC-CMs at the Early stage of differentiation (Figure 1A) [23].

Table 1 Main developmental changes of ionic currents

\begin{tabular}{|c|c|c|c|c|c|}
\hline & Parameter (units) & Early & Late & Adult [16] & Species [Ref.] \\
\hline$I_{\text {to }}$ & $\mathrm{G}_{\text {to }}(\mathrm{S} / \mathrm{F})$ max conductance & 19.2929 & 48.702 & 294 & human, EXP, †; human, MOD, [16] \\
\hline $\mathrm{I}_{\mathrm{Kr}}$ & $\mathrm{G}_{\mathrm{Kr}}(\mathrm{S} / \mathrm{F})$ max conductance & 288.0 & 134.4 & 96 & $\begin{array}{l}\text { rat, guinea pig, EXP, [24]; human, } \\
\text { MOD, }[16]\end{array}$ \\
\hline$l_{f}^{*}$ & $\mathrm{G}_{\mathrm{f}}(\mathrm{S} / \mathrm{F})$ max conductance & 49 & 20.913 & - & human, EXP, [6] \\
\hline $\mathrm{I}_{\mathrm{K} 1}^{*}$ & $\mathrm{G}_{\mathrm{K} 1}(\mathrm{~S} / \mathrm{F})$ max conductance & 240.523 & 1154.508 & 5405 & human, EXP, [6]; human, MOD, [16] \\
\hline $\mathrm{I}_{\mathrm{CaL}}^{*}$ & $\mathrm{G}_{\mathrm{CaL}}\left(\mathrm{dm}^{3} /(\mathrm{F} \cdot \mathrm{s})\right)$ permeability & 0.0438 & 0.0739 & 0.175 & $\begin{array}{l}\text { mouse, EXP, [24]; human, EXP. } \\
\text { [6]human, MOD, [16] }\end{array}$ \\
\hline $\mathrm{I}_{\mathrm{CaT}}$ & $\mathrm{G}_{\mathrm{CaT}}(\mathrm{S} / \mathrm{F})$ max conductance & 45.8 & 9.16 & - & human, EXP, †; rabbit, MOD, [27] \\
\hline $\mathrm{I}_{\mathrm{NaCa}}^{*}$ & $I_{\operatorname{maxNaCa}}(A / F)$ max current & 17500 & 18240 & 1000 & human, EXP, †; human, MOD, [16] \\
\hline $\mathrm{I}_{\mathrm{Na}}$ & $\mathrm{G}_{\mathrm{Na}}(\mathrm{S} / \mathrm{F})$ max conductance & 563.844 & 14838 & 14838 & mouse, EXP, [24]; human, MOD, [16] \\
\hline $\mathrm{I}_{\mathrm{Ks}}$ & $\mathrm{G}_{\mathrm{Ks}}(\mathrm{S} / \mathrm{F})$ max conductance & 15.7 & 15.7 & 157 & human, EXP, [32]; human, MOD, [16] \\
\hline $\mathrm{I}_{\mathrm{NaK}}$ & $I_{\operatorname{maxNaK}}(A / F)$ max current & 0.9534 & 1.1305 & 1.362 & mouse, EXP, [34]; human, MOD, [16] \\
\hline $\mathrm{I}_{\mathrm{pCa}}$ & $\mathrm{G}_{\mathrm{pCa}}(\mathrm{S} / \mathrm{F})$ max conductance & $0.825, \S$ & $0.825, \S$ & 25 & human, MOD, [16] \\
\hline $\mathrm{I}_{\text {up }}$ & $I_{\max \cup p}(\mathrm{mM} / \mathrm{s}) \max$ flux & 0.0565 & 0.1403 & 0.425 & mouse, EXP, [24]; human, MOD, [16] \\
\hline Irel & $I_{\text {maxRel }}(\mathrm{mM} / \mathrm{s})$ max flux & 0.274 & 9.88 & 24.7 & mouse, EXP, [24]; human, MOD, [16] \\
\hline$I_{\text {leak }}$ & $I_{\text {maxLeak }}(1 / \mathrm{s})$ max rate & 0.0004 & 0.024 & 0.08 & mouse, EXP, [24]; human, MOD, [16] \\
\hline $\mathrm{I}_{\mathrm{bCa}}$ & $\mathrm{G}_{\mathrm{bCa}}(\mathrm{S} / \mathrm{F})$ max conductance & $0.118, \S$ & $0.592, \S$ & 0.592 & human, MOD, [16] \\
\hline
\end{tabular}

Maximum conductances, currents and fluxes for Early and Late human embryonic stem cell-derived and adult ventricular cardiomyocyte models. The species considered for the Early and Late date are reported. Adult data refers to the TenTusscher model [16]. † new measurements and data; $\S$ values chosen to reproduce at best the AP shape; ${ }^{*}$ not only the maximal conductance/current was changed but also the current formulation (see Additional file 1). EXP: experimental data; MOD: used for modelling. 


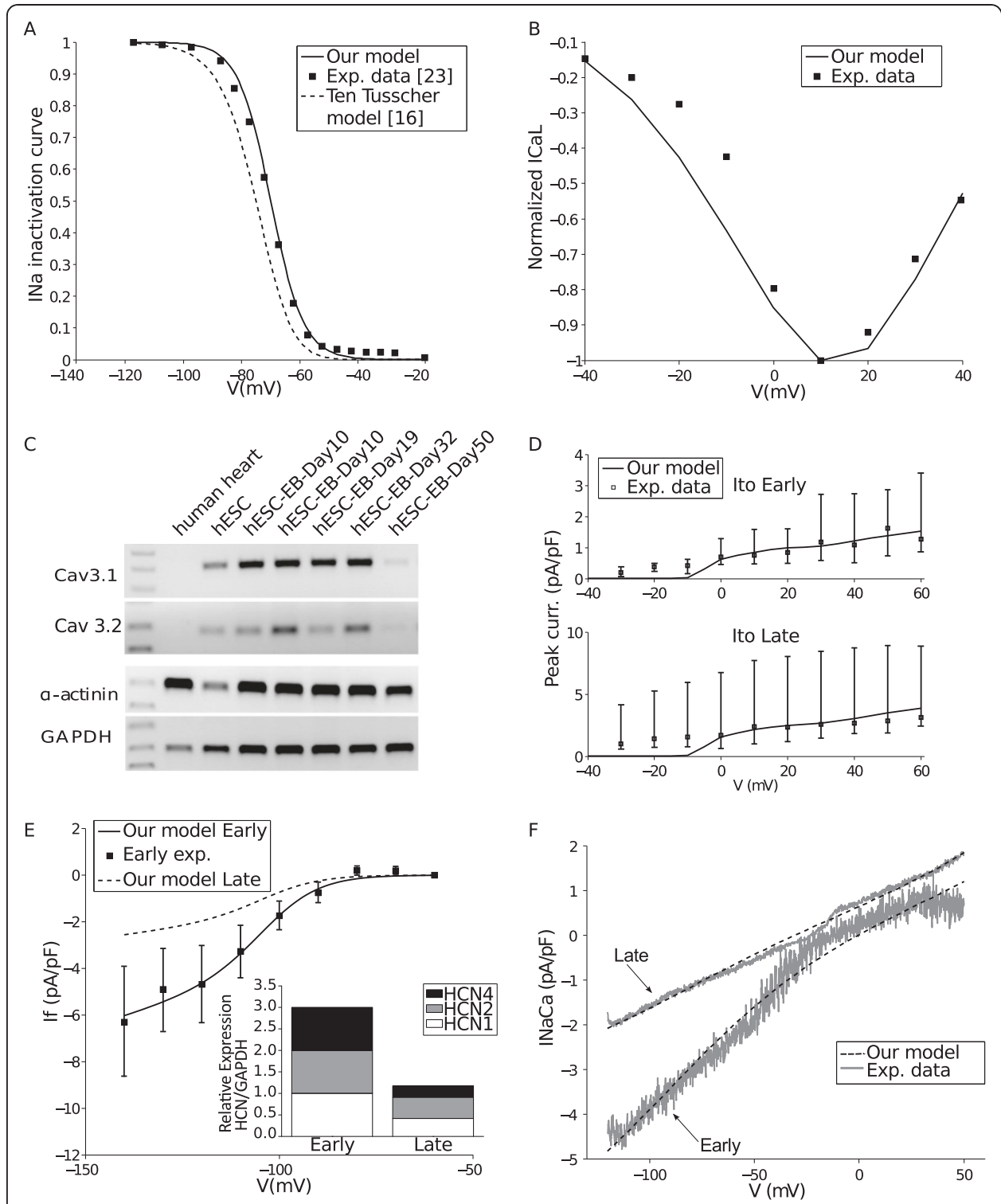

Figure 1 Currents: experimental data and model fitting. (A) $I_{\mathrm{Na}}$ inactivation for Early human embryonic stem cell-derived cardiomyocytes (hESC-CMs). (B) $I_{\text {CaL }}$ normalized current-voltage (IN) curve (Late stage). (C) Cav3.1, Cav3.2 and GADPH expression ( $I_{\text {CaT }}$ ) for H1-hESC-CMs. (D) $I_{\text {to }} I / N$ curves. (E) $I_{f} I / N$ curves and HCN quantitative expression (inset). (F) $I_{\mathrm{NaCa}}$ elicited by a voltage ramp protocol

As also reported in [24] for rodent ESC-CMs we considered a small expression of $\mathrm{I}_{\mathrm{Na}}$ at the Early stage and full expression at the Late one; the expression at the Early stage was further reduced with respect to [24] (from 0.08 to 0.038) in order to fit properly our experimental maximal upstroke velocity (Vmax) and the action potential duration (APD).

$$
R a I_{N a}=0.038\left(\text { Early); } R a I_{N a}=1(\text { Late })\right.
$$

L-type calcium current $\left(I_{\text {Cal }}\right)$

Due to lack of specific data on $\mathrm{I}_{\mathrm{CaL}}$ at the Early stage, we tuned the permeability, the $\mathrm{Ca}^{2+}$ dependent inactivation gate, $f_{C a}$ (Additional file 1: Eqs. S25-S31), the time 
constant of the voltage dependent inactivation gate, $\tau_{f}$ (Additional file 1: Eq. S33), and the steady-state activation gate, $d_{\infty}$ (Additional file 1: Eq. S19) to reproduce the experimental features of AP, in particular APD.

We then slightly modified $d_{\infty}$ in order to fit our experimental recordings of $\mathrm{I}_{\mathrm{CaL}}$ at Late developmental stage (Figure $1 \mathrm{~B}$, Late stage, $\mathrm{n}=1$ ), whereas inactivation parameters became equal to those of adult CMs in the Late stage formulation. We maintained the ratio between Late and Early conductances proposed in [24] based on data in mice and guinea pigs:

$$
R a I_{C a L}=0.25 \text { (Early); RaI } I_{C a L}=0.422 \text { (Late) }
$$

\section{T-type calcium current ( $\left.I_{\text {CaT }}\right)$}

At variance with the adult model, we included $\mathrm{I}_{\mathrm{CaT}}$, on the basis of different experimental evidence. First, $\mathrm{I}_{\mathrm{CaT}}$ was reported to be highly expressed during fetal heart development and gradually decline after birth, becoming restricted to the conduction and pacemaker cells [25]. Secondly, $\mathrm{I}_{\mathrm{CaT}}$ is functionally expressed in mouse ESC and is downregulated during cardiac differentiation: $\mathrm{I}_{\mathrm{CaT}}$ channel subunits Cav3.1 and Cav3.2 expression decreased to approximately $46 \%$ and $24 \%$, respectively, at 23.5 days of differentiation with respect to 9.5 days [26]. Finally, our qualitative RT-PCR measurements in H1-hESC-CMs show a clear expression of Cav3.1 and Cav3.2 at both stages (Figure 1C). We used the $\mathrm{I}_{\mathrm{CaT}}$ formulation proposed in [27] in their sinoatrial node cell model, with progressively decreasing scaling factors for the maximal conductance:

$$
R a I_{C a T}=0.25 \text { (Early); RaI } I_{C a T}=0.05 \text { (Late) }
$$

\section{Transient outward $\left(I_{t o}\right)$, rapid and slow delayed rectifier $\left(I_{K_{r}} I_{K s}\right) K^{+}$currents}

$\mathrm{I}_{\text {to }}$ properties were based on original data obtained in H1-hESC-CMs. Figure 1D shows the I/V relationship for peak $\mathrm{K}^{+}$currents evoked by depolarizing steps in Early and Late CMs (median data and interquartile, $n=10$ Early stage and $n=9$ Late stage). A $10 \mathrm{mV}$ positive shift was applied to experimental data to account for the use of $\mathrm{Cd}^{2+}$ to block $\mathrm{I}_{\mathrm{CaL}}$, as done by [28]. According to our previous observations [6], $I_{\text {to }}$ activation properties are similar to those described in native cardiac cells. Maximum conductances and steady-state activation were calculated by fitting experimental data (Figure 1D and Additional file 1: Eq. S43):

$$
\operatorname{RaI}_{t o}=0.065622(\text { Early }) ; R^{2} I_{t o}=0.165653(\text { Late })
$$

In accordance with various in vivo and in vitro experimental data in fetal guinea pigs [20] rats [29,30], and mice [31], $\mathrm{I}_{\mathrm{Kr}}$ maximal conductance was greater than in the adult CMs and it decreased during maturation, we chose the specific expression ratios in order to mimick maximum diastolic potential (MDP) and the APD at the different developmental stages:

$$
R a I_{K r}=3 \text { (Early); } R a I_{K r}=1.4 \text { (Late) }
$$

$\mathrm{I}_{\mathrm{Ks}}$ conductance in the Early developmental stage was set in order to achieve a good fitting of the I/V curve (Additional file 1: Figure S1) obtained by [32] on Early hESC-CMs. On the basis of data on embryonic murine heart $[19,24]$, where 
Early and Late developmental stages seem to share the same $\mathrm{I}_{\mathrm{Ks}}$ conductance, a single value of $\mathrm{RaI}_{\mathrm{Ks}}$ was used:

$$
R a I_{K s}=0.1 \text { (Early and Late); }
$$

\section{Inward rectifier $K^{+}$current $\left(I_{K 1}\right)$}

In hESC-CMs $\mathrm{I}_{\mathrm{K} 1}$ is very small but not absent at the Early stage, then it increases during the development, as also reported for rat and guinea pig [24]. Conductances were identified according to our previous data [6], showing a ratio between Late and Early current density at $-90 \mathrm{mV}$ of 5.42 . In order to reduce the MDP we set in our model a ratio of 4.8 , within the variability of our data and introduced a shift of the voltage dependence for the inward rectification factor, $\mathrm{x}_{\mathrm{k} 1 \infty}$ (Additional file 1: Eqs. S67-S69), without modifying the current reversal potential.

$$
R a I_{K 1}=0.0445 \text { (Early); } R a I_{K 1}=0.2136 \text { (Late) }
$$

\section{Funny current $\left(I_{f}\right)$}

A key step of the formulation of a specific hESC-CM model consisted in integrating the hyperpolarization-activated cyclic nucleotide-gated or funny current, that is reported to be one of the main contributor for the spontaneous beating of pacemaker cells [33] and hESC-CMs [6]. If formulation (Additional file 1: Eqs. S71-S73) and conductance were obtained by fitting recordings performed on Early H1hESC-CMs (Figure 1E, Early stage, $\mathrm{n}=4$ ).

For the Late stage, in accordance to our previous data [6], we assumed that current density decreased over maturation to an extent equal to the drop of cumulative $\mathrm{HCN}$ transcript expression (Figure 1E, inner panel): the estimated ratio between Early and Late stage was 2.34 .

$$
R a I_{f}=0.5389(\text { Early); RaI }=0.23 \text { (Late) }
$$

\section{Sodium-potassium pump ( $\left.I_{\text {NaK }}\right)$ and sodium-calcium exchanger ( $\left.I_{\text {NaCa }}\right)$}

Since data on hESC-CM $\mathrm{I}_{\mathrm{NaK}}$ were not available, maximal current density was set taking into account its influence on the diastolic depolarization rate (DDR) and frequency of spontaneous beating (F) and reflecting the maturation related growth of INaK expression according to experiments by [34] on mouse ESC-CMs:

$$
R a I_{\text {NaK }}=0.7(\text { Early }) ; R a I_{\text {NaK }}=0.83(\text { Late })
$$

As far as $\mathrm{I}_{\mathrm{NaCa}}$ is concerned, we used original experimental data from H1-hESC-CMs. Voltage ramp (from -120 to ${ }^{+} 50 \mathrm{mV}$ ) protocols elicited an almost linear $\mathrm{I}_{\mathrm{NaCa}} \mathrm{I} / \mathrm{V}$ relationship (Figure $1 \mathrm{~F}, \mathrm{n}=6$ ) that showed an inward and outward mode at both developmental stages. Fitting of experimental data led to modify the original maximal current density and the extra factor $\alpha$ in the $\mathrm{I}_{\mathrm{NaCa}}$ expression [16]:

$$
\begin{aligned}
R a I_{N a C a} & =17.50 \text { (Early); RaI } I_{N a C a}=18.24 \text { (Late) } \\
a & =0.8 \text { (Early), } a=0.38 \text { (Late) }
\end{aligned}
$$

\section{Sarcoplasmic reticulum (SR) currents}

The maximal values for the uptake $\left(\mathrm{I}_{\text {up }}\right)$, release $\left(\mathrm{I}_{\text {rel }}\right)$ and leakage $\left(\mathrm{I}_{\text {leak }}\right)$ currents were tuned to simulate the ryanodine induced reduction of $\mathrm{Ca}^{2+}$ transient amplitude 
reported in [11] at the Early and in [12] at the Late stage. Increases in maximal current densities at the Late stage were based on the rodent ESC-CM model [24].

$$
\begin{aligned}
R a I_{U p} & =0.133(\text { Early }) ; R a I_{\text {Up }}=0.33(\text { Late }) \\
R a I_{\text {Rel }} & =0.0111(\text { Early }) ; R a I_{\text {Rel }}=0.4(\text { Late }) \\
R a I_{\text {Leak }} & =0.005556(\text { Early }) ; R a I_{\text {Leak }}=0.3(\text { Late })
\end{aligned}
$$

\section{Sarcolemmal calcium pump, $I_{p C a}$ and background current, $I_{b C a}$}

Since data about these currents are not available, we chose the following values to reproduce at best the AP shape:

$$
\begin{aligned}
& R a I_{C a p}=0.033(\text { Early and Late); } \\
& R a I_{b C a}=0.2(\text { Early }) ; R a I_{b C a}=1 \text { (Late); }
\end{aligned}
$$

\section{Cell capacitance and dimensions}

Median values of measured cell membrane capacitance were used to set cell dimensions (see Additional file 1).

\section{Sensitivity analysis}

A sensitivity analysis was performed according to the procedure reported in [35,36], opportunely adapted to our model. The main differences with respect to [35] are: (i) our hESC-CM model is not stimulated by an external source and (ii) we concentrate our analysis on the impact of the ratios $\mathrm{RaI}_{\mathrm{xx}}$ on the AP shape. One ratio was varied at time by $-20 \%,-10 \%,+10 \%$ and $+20 \%$ respectively.

Considering the following ratios (parametrs) "p"

$$
\mathrm{p}=\left\{\operatorname{RaI}_{\mathrm{Na}}, \operatorname{RaI}_{\mathrm{CaL}}, \operatorname{RaI}_{\mathrm{f}}, \operatorname{RaI}_{\mathrm{to}}, \operatorname{RaI}_{\mathrm{K} 1}, \operatorname{RaI}_{\mathrm{Kr}}, \operatorname{RaI}_{\mathrm{Ks}}, \operatorname{RaI}_{\mathrm{NaK}}, \operatorname{RaI}_{\mathrm{NaCa}}\right\}
$$

and the AP features (characteristics) "c"

$$
\mathrm{c}=\{\mathrm{MDP}, \mathrm{Vmax}, \mathrm{APD} 30, \mathrm{APD} 50, \mathrm{APD} 70, \mathrm{APD} 90, \mathrm{DDR}, \mathrm{F}\},
$$

computed after 300 seconds of simulation (assuming the steady state condition) the indexes percentage of change $\left(D_{c, p, a}\right)$, sensitivities $\left(S_{c, p,+20 \%}\right.$ and $\left.S_{c, p,-20 \%}\right)$ and relative sensitivities $\left(\mathrm{r}_{\mathrm{c}, \mathrm{p},+20 \%}\right.$ and $\left.\mathrm{r}_{\mathrm{c}, \mathrm{p},-20 \%}\right)$ were calculated as follows:

$$
\begin{aligned}
& D_{c, p, a}=\frac{\left(C_{p, a}+C_{c o n t r o l}\right)}{C_{c o n t r o l}} \cdot 100 \\
& S_{c, p,+20 \%}=\frac{D_{c, p,+20 \%}}{0.2}, S_{c, p,-20 \%}=-\frac{D_{c, p,-20 \%}}{0.2} \\
& r_{c, p,+20 \%}=\frac{S_{c, p,+20 \%}}{\left|S_{c, p,+20 \%}\right|_{\max , c}}, r_{c, p,-20 \%}=\frac{S_{c, p,-20 \%}}{\left|S_{c, p,-20 \%}\right|_{\max , c}}
\end{aligned}
$$

Splitting the original $S_{c, p}$ and $r_{c, p}$ [35] was necessary since several tests resulted in no spontaneous APs, thus making impossible calculating the AP features and all their $\mathrm{D}_{\mathrm{c}, \mathrm{p}, \mathrm{a}}$. However, for each ratio at least one $D_{c, p, a}\left(D_{c, p,+20 \%}\right.$ or $\left.D_{c, p,-20 \%}\right)$ was available thus allowing to get the asymmetrical sensitivities.

\section{Interaction with in silico fibroblasts}

In order to preserve intracellular milieu and cell-to-cell communication, AP recordings were not performed on single cells but on EBs, aggregates containing different cell 
phenotypes among which hESC-CMs and fibroblasts. To test the interaction between these kinds of cells and assess the effect on AP simulation, an additional mammalian fibroblast model, resistively coupled to the hESC-CM, was developed according to [3739]. To this aim, the hESC-CM membrane potential equation was modified as follows:

$$
\begin{gathered}
\frac{d V}{d t}=-\frac{I_{\text {ion }}+N_{f} \cdot I_{\text {gap }}}{C_{m}}, \\
I_{\text {gap }}=G_{\text {gap }}\left(V-V_{\text {fibro }}\right),
\end{gathered}
$$

where $\mathrm{V}_{\text {fibro }}$ is the fibroblast potential, $\mathrm{G}_{\text {gap }}$ is the conductance of the $\mathrm{hESC}$-CM-fibroblast coupling $\left(G_{g a p}=1 n S\right)$ and $\mathrm{N}_{\mathrm{f}}$ is the number of coupled fibroblasts. Details on the fibroblast model are reported in the Additional file 1 (Additional file 1: Eqs. S92-S94).

\section{Drug simulations}

To reproduce the inhibition of $\mathrm{SR} \mathrm{Ca}^{2+}$ release and the consequent $\mathrm{Ca}^{2+}$ transient reduction in ryanodine experiments the simulation was performed zeroing $I_{u p}$ and $I_{\text {rel }}$. To simulate $\mathrm{E} 4031$ ( $\mathrm{I}_{\mathrm{Kr}}$ blocker) and nickel ( $\mathrm{I}_{\mathrm{CaT}}, \mathrm{I}_{\mathrm{Kr}}$ and $\mathrm{I}_{\mathrm{NaCa}}$ blocker) effects, in steady state conditions, a step reduction of conductance for the targeted currents was implemented in the model. The amount of conductance reduction for each current, which is reported in the Results Section, was chosen within the range of blocking action of the drug in order to better reproduce the specific experimental result obtained on a single cluster of hESC-CMs.

\section{Numerical implementation}

Differential equations were implemented in MATLAB (The MathWorks, Natick, MA) and solved using ode15s.

\section{Results}

hESC-CM model

Figure 2A shows simulated AP profiles for Early hESC-CMs obtained using our model: the modifications introduced with respect to the adult ventricular model were sufficient to elicit spontaneous beating. A comparison with experimental Early AP profiles obtained on intact EBs by multicellar recordings is provided in Table 2: a global comparison was done by calculating typical morphological parameters (AP features) for both experimental and simulated APs. This analysis demonstrated that our hESC-CM model was able to reproduce most of the experimental AP features, including AP duration (APD) at $30\left(\mathrm{APD}_{30}\right), 50$ $\left(\mathrm{APD}_{50}\right), 70\left(\mathrm{APD}_{70}\right)$ and $90 \%\left(\mathrm{APD}_{90}\right)$ of repolarization, $\mathrm{Vmax}, \mathrm{F}$ and the DDR. Simulated and experimental data differed for the MDP, which is more negative in the simulation.

\section{Transition from Early to Late stage of development: effects of maturation}

The simulated AP profile at the Late stage and the comparison with experimental APs obtained on intact EBs by multicellar recordings are reported in Figure 2B and Table 2, respectively. These results show that the changes introduced in the model parameters between the Early and Late stage allow to reproduce the documented [6] maturation effects on AP shape. In particular, during the transition from the Early to the Late 


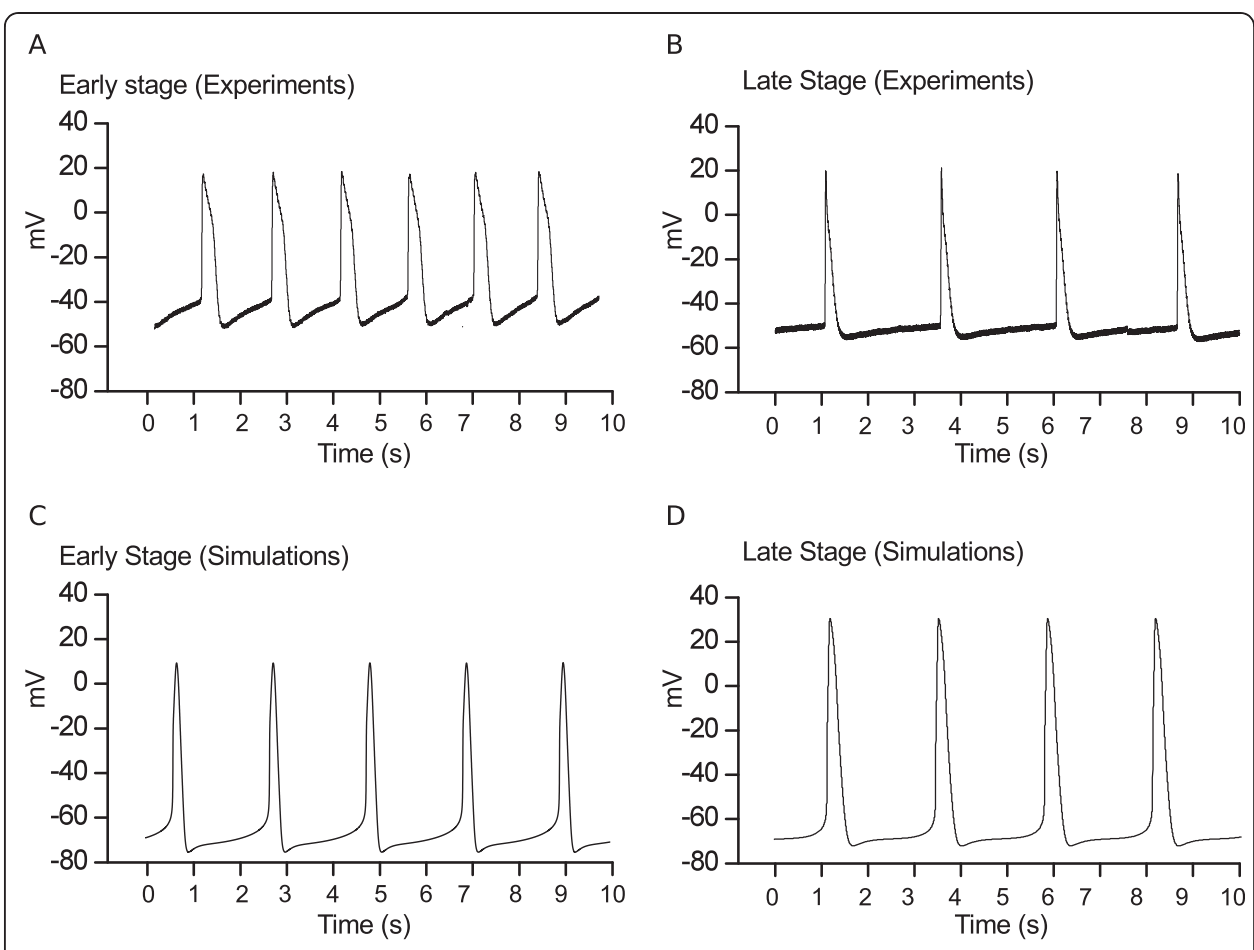

Figure 2 Action Potential simulations. Simulated action potentials for Early (A) and Late (B) hESC-CMs clusters

stage, APD and Vmax increase while spontaneous rate and slope of diastolic depolarization decrease.

\section{Spontaneous firing and action potential shape dependence on current conductances}

The sensitivity analysis performed on the Early and Late models was aimed to assess how variations in the maximum conductances of the most important membrane currents affect (i) the phenomenon of spontaneous beating and (ii) the AP shape.

The spontaneous firing activity was not triggered at the Early stage in 2 tests only: $\mathrm{RaI}_{\mathrm{CaL}}-20 \%$ and $\mathrm{RaI}_{\mathrm{NaCa}}+20 \%$. At the Late stage the spontaneous activity showed to

Table 2 Action potential features of experimental and simulated action potentials

\begin{tabular}{|c|c|c|c|c|c|c|}
\hline & \multicolumn{2}{|l|}{ Early } & \multicolumn{2}{|l|}{ Late } & \multicolumn{2}{|c|}{ Delta \% } \\
\hline & $\operatorname{Exp}$ & Sim & Exp & Sim & $\operatorname{Exp}$ & Sim \\
\hline $\mathrm{APD}_{30}$ (ms) & $117(107 \div 132)$ & 121 & $163(84 \div 256)$ & 165 & +40 & +36 \\
\hline $\mathrm{APD}_{50}$ (ms) & $169(149 \div 184)$ & 163 & $258(148 \div 374)$ & 224 & +53 & +37 \\
\hline $\mathrm{APD}_{70}$ (ms) & $205(181 \div 219)$ & 191 & $325(179 \div 465)$ & 283 & +59 & +48 \\
\hline APD 90 (ms) & $229(216 \div 241)$ & 225 & $419(223 \div 506)$ & 350 & +83 & +56 \\
\hline$V \max (m V / s)$ & $4610(3308 \div 5612)$ & 4123 & $5566(5198 \div 7047)$ & 5620 & +42 & +36 \\
\hline $\mathrm{MDP}(\mathrm{mV})$ & $-55(-62 \div-37)$ & -76 & $-51(-62 \div-42)$ & -73 & -7 & -4 \\
\hline DDR (mV/s) & $14.4(11.1 \div 28.4)$ & 9.7 & $9.9(8.0 \div 11.1)$ & 7.1 & -31 & -27 \\
\hline $\mathrm{F}(\mathrm{bpm})$ & $27(23 \div 53)$ & 29 & $22(20 \div 29)$ & 24 & -17 & -17 \\
\hline
\end{tabular}

Delta \%, Late VS Early; APD, action potential duration; $\mathrm{V}_{\max }$ maximum upstroke velocity; MDP maximum diastolic potential; DDR diastolic depolarization rate; F frequency. Data reported as median and interquartile. All the experimental action potential features were measured on hESC-CM AP at the Early and Late stage [50]. 
be sensitive to more currents: the firing activity was triggered but stop after few dozens of seconds of simulations for $\mathrm{RaI}_{\mathrm{Na}}+20 \%, \mathrm{RaI}_{\mathrm{CaL}}-20 \%, \mathrm{RaI}_{\mathrm{f}}-20 \%, \mathrm{RaI}_{\mathrm{K} 1}+20 \%, \mathrm{RaI}_{\mathrm{Kr}}$ $+20 \%, \mathrm{RaI}_{\mathrm{NaK}}+20 \%$ and $\mathrm{RaI}_{\mathrm{NaCa}}+20 \%$.

When the spontaneous beating allowed to reach a steady state condition, the AP features absolute/relative sensitivities were computed (Figure 3) as reported in the Methods section. At the Early stage MDP is affected by the inward $\mathrm{I}_{\mathrm{CaL}}, \mathrm{I}_{\mathrm{NaCa}}$ (inward during the late-repolarization) and the outward $\mathrm{I}_{\mathrm{Kr}}$. The effect of $\mathrm{I}_{\mathrm{f}}$ is extremely small, since at the MDP potential it is not activated yet, due to its high time constant. Also the $I_{K 1}$ effect is small since at this developmental stage the $I_{K 1}$ expression is low. The Late stage shows a more stable MDP (maximum variations: 7-8\%), but the $\mathrm{I}_{\mathrm{K} 1}$ effect is stronger, as consequence of a maturation-related increment in $\mathrm{I}_{\mathrm{K} 1}$ expression. As expected, Vmax is mainly affected at both stages by the inward currents mainly acting during the upstroke: $\mathrm{I}_{\mathrm{Na}}$ and $\mathrm{I}_{\mathrm{CaL}}$, while the rate of spontaneous beating resulted to be more sensitive to $\mathrm{I}_{\mathrm{CaL}}, \mathrm{I}_{\mathrm{NaK}}, \mathrm{I}_{\mathrm{NaCa}}, \mathrm{I}_{\mathrm{f}}$ (Early stage)and $\mathrm{I}_{\mathrm{K} 1}$ (Late stage). $\mathrm{I}_{\mathrm{CaL}}, \mathrm{I}_{\mathrm{NaK}}$ and $\mathrm{I}_{\mathrm{K} 1}$ had the most strong effect on DDR and F at both stages; these AP features show also an important sensitivity to $\mathrm{I}_{\mathrm{f}}$ increments at the Early stage. It is interesting to note that also $\mathrm{I}_{\mathrm{NaCa}}$ reduction increase DDR and $\mathrm{F}$ at both stages but particularly at the Early one: a smaller $\mathrm{I}_{\mathrm{NaCa}}$ (inward during late-repolarization) makes MDP more negative $\left(-81 \mathrm{mV}\right.$ vs $-76 \mathrm{mV}, \mathrm{RaI}_{\mathrm{NaCa}}-20 \%$ and control respectively) allowing a greater activation of $I_{f}$ and thus increasing both DDR and F. Variations of the outward currents $I_{K 1}$ and $\mathrm{I}_{\mathrm{NaK}}$ show the role of these currents in stabilizing the diastolic potential and, at the Late stage, increments block the spontaneous beating. APD is mainly affected by the inward currents $\mathrm{I}_{\mathrm{CaL}}$ and $\mathrm{I}_{\mathrm{Na}}$, by $\mathrm{I}_{\mathrm{NaCa}}$ (outward during the upstroke), $\mathrm{I}_{\mathrm{NaK}}$ (Late only) and the outward $I_{K n}$ especially during the late-repolarization. At the Early stage, the APD decreases after $\mathrm{I}_{\mathrm{CaL}}$ increments: this counterintuitive result can be explained by using the model. In fact, it is due to a higher AP peak $\left(20 \mathrm{mV}\right.$ vs $8.3 \mathrm{mV}, \mathrm{RaI}_{\mathrm{CaL}}+20 \%$ vs control): the higher reached membrane potential allows a stronger $\mathrm{I}_{\mathrm{Kr}}$ activation thus reducing $\mathrm{APD}$. At the Late stage this phenomenon is not present, since in the AP peak increment is smaller ( $34.2 \mathrm{mV}$ vs $30.2 \mathrm{mV}, \mathrm{RaI}_{\mathrm{CaL}}+20 \%$ vs control), and $\mathrm{I}_{\mathrm{Kr}}$ itself is smaller due to maturation. This different contribution of inward/outward currents to APD likely underlies the diverse APD rate-dependence (Additional file 1: Figure S2).

\section{Coupling with fibroblasts}

In order to partially overcome the discrepancy in MDP between the model and the experimental measurements, we introduced the contribution of fibroblasts, which are an essential component of EBs also for CM maturation. To assess the relevance of this issue in our model, we considered a simple system composed of a single hESC-CM coupled with 1 and 2 fibroblasts for each stage. Changes in basal AP due to fibroblast coupling are reported in Figure 4A and 4C, for the Early and Late phase, respectively, while a quantification of these changes is summarized in Figure 4B and 4D. Changes in most of the AP features as a function of fibroblast number were similar between the two stages. In particular, we observed an increment in DDR and rate while AP amplitude (APA) decreased. The effect on APD was different in the two stages. In the Early hESC-CM, lacking the plateau phase, the major effect is an inward current flowing from the coupled fibroblasts into the hESC-CM during the late repolarization phase, when hESC-CM membrane potential is negative to the fibroblast resting potential, 


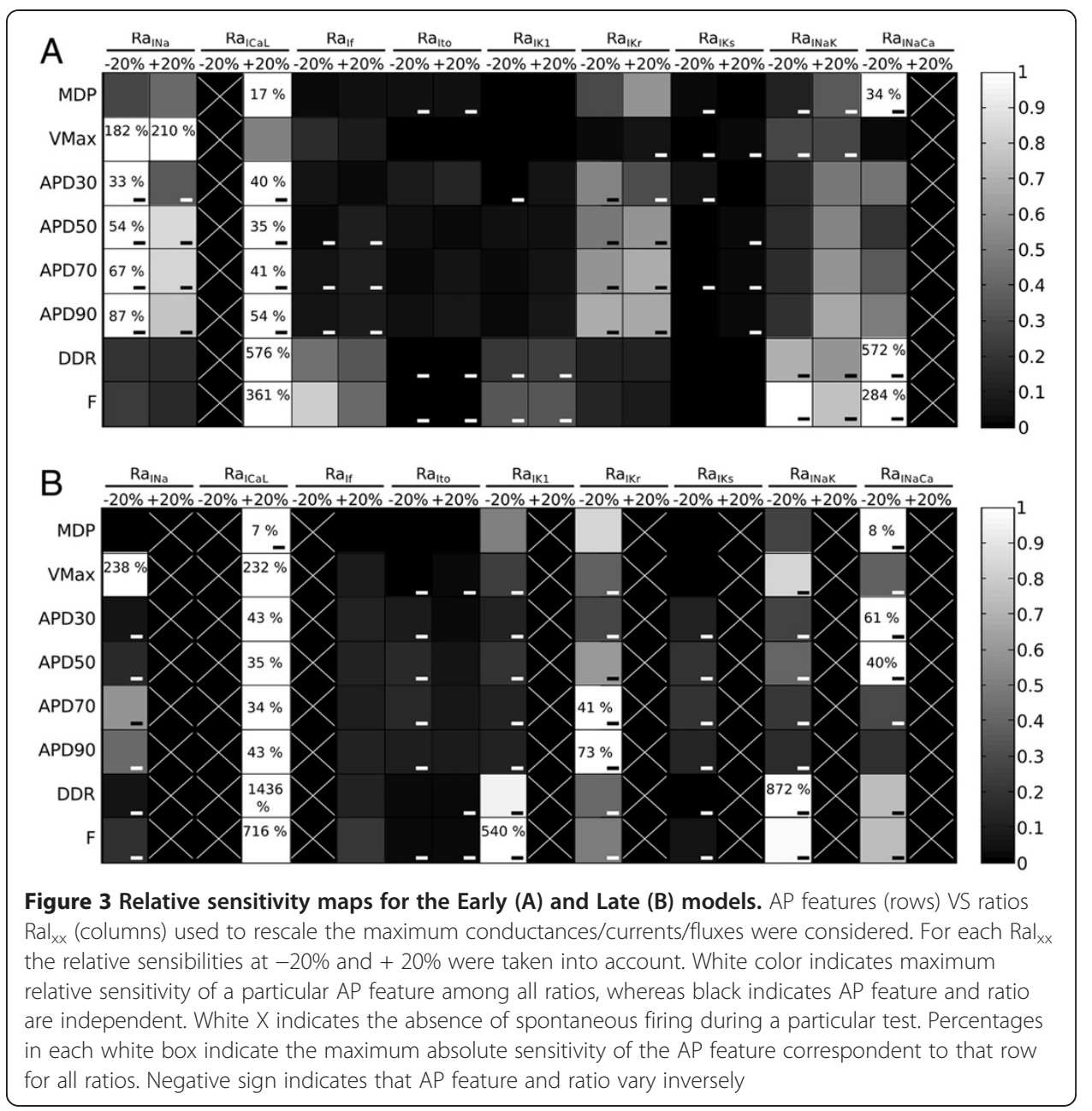

promoting slowing of repolarization and APD increase. In the Late hESC-CM, showing significantly longer AP with respect to Early, the effect of an outward current, flowing towards coupled fibroblasts at depolarized potential and promoting hESC-CM repolarization and APD decrease, is also important. The overall result in Late hESC-CM is a decrease of $\mathrm{APD}_{30}$ and $\mathrm{APD}_{50}$ whereas $\mathrm{APD}_{70}$ and $\mathrm{APD}_{90}$ were almost not affected by coupling with fibroblasts. Importantly, as the number of coupled fibroblast increases from 0 to 2, a small rising of MDP occurred both at Early (-76 to $-73 \mathrm{mV})$ and Late stage $(-73$ to $-72 \mathrm{mV})$. This effect was accompanied by a reduction of Vmax at Early ( 4123 to $3443 \mathrm{mV} / \mathrm{s}$ ) and Late stage ( 5620 to $2554 \mathrm{mV} /$ s). At the same time, the membrane potential of coupled fibroblasts mimics the hESC-CM AP (data not shown), oscillating between -74 and $4 \mathrm{mV}$ at the Early and between -72 and $26 \mathrm{mV}$ at the Late stage.

\section{Intracellular calcium}

To assess the relevance of RyR-mediated $\mathrm{SR} \mathrm{Ca}^{2+}$ release in our model, we simulated cytoplasmic $\mathrm{Ca}^{2+}$ oscillations in control conditions and after blockade of $\mathrm{Ca}^{2+}$ release. In control conditions, the Early model showed intracellular $\mathrm{Ca}^{2+}$ diastolic 


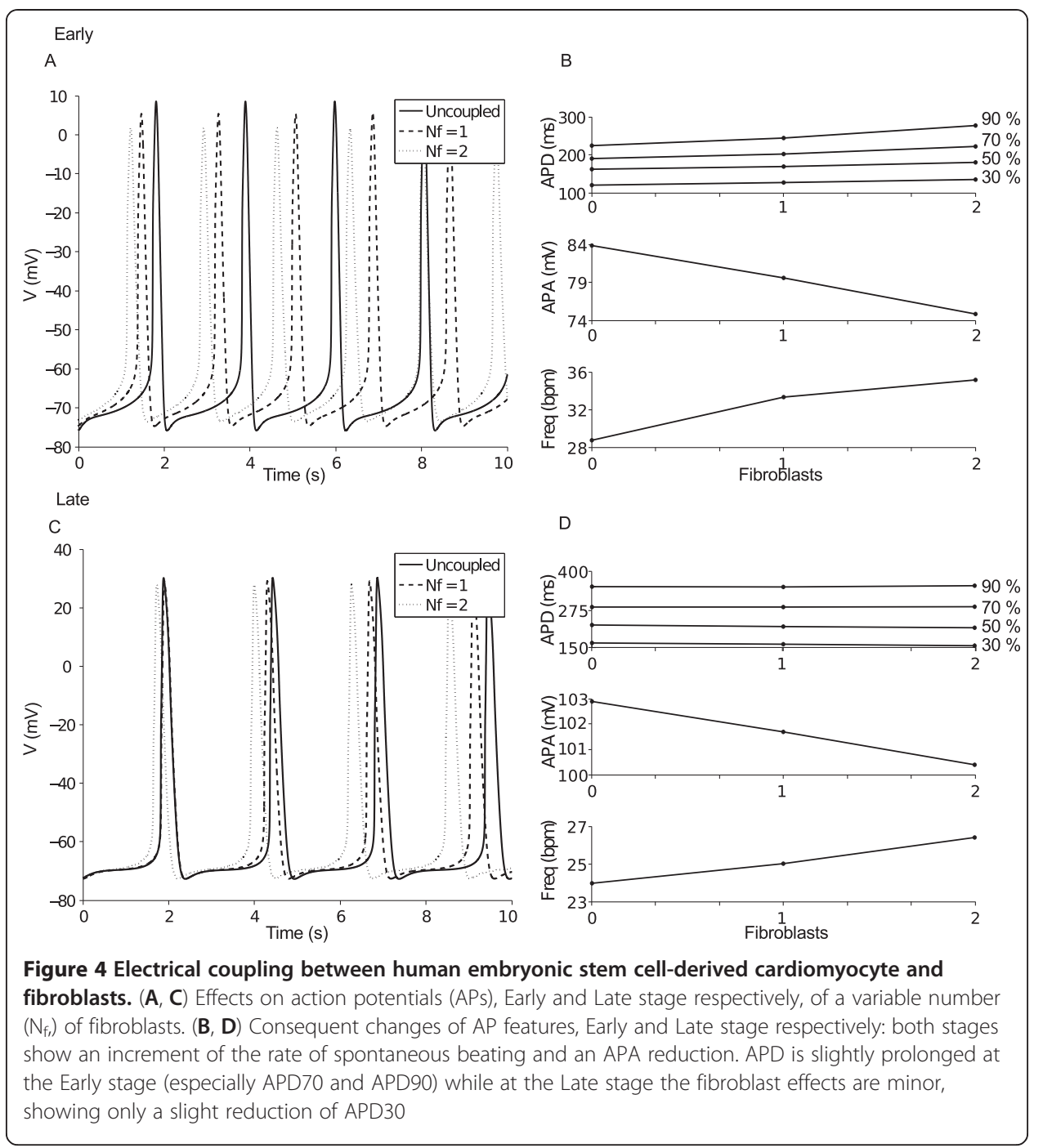

and systolic concentrations of $0.026 \mu \mathrm{M}$ and $0.141 \mu \mathrm{M}$, respectively, with an amplitude of the transient of $0.115 \mu \mathrm{M}$. The mean rate of decay was $0.123 \mu \mathrm{M} / \mathrm{s}$ while the maximum upstroke velocity (VmaxCa,upstroke) was $1 \mu \mathrm{M} / \mathrm{s}$ and the maximum decay velocity (VmaxCa,decay) was $0.52 \mu \mathrm{M} / \mathrm{s}$. Control values for the Late model were $0.063 \mu \mathrm{M}$ and $0.506 \mu \mathrm{M}$ for diastolic and systolic concentrations, $0.443 \mu \mathrm{M}$ and $0.340 \mu \mathrm{M} / \mathrm{s}$ for amplitude and mean rate of decay. VmaxCa,upstroke was 13 $\mu \mathrm{M} / \mathrm{s}$ and $\mathrm{VmaxCa}$,decay was $1.4 \mu \mathrm{M} / \mathrm{s}$.

The blockade of the SR channels and pumps reduced the $\mathrm{Ca}^{2+}$ oscillation amplitude by only $12 \%$ at the Early stage, whereas the RyR-induced reduction was larger, $33 \%$, at the Late stage (Figure 5A and 5B). These results are similar to those reported experimentally in H1-CMs by [11] after 18-24 days and by [12] in cells assessed 30-40 days "post-beating", likely corresponding to 50 days of total time of differentiation. A more detailed comparison was performed between the data reported in [11] on caffeinesensitive H1-CMs and our Early stage, also considering the transient elicited in [11] in stimulation condition. In order to compare the experimental and simulated $\mathrm{VmaxCa}$, upstroke and VmaxCa,decay in control conditions we normalized them using the 
amplitude of the transient, since experimental data were reported in terms of fluorescence while ours as concentration values. Estimating from [11] transient amplitude 0.16 F340/ 380 and VmaxCa,upstroke 1.5 F340/380/s we got a normalized VmaxCa,upstroke of 9.3 1/s. Normalizing our Early VmaxCa,upstroke, our model reproduced 8.7 1/s. Comparing in the same manner the VmaxCa,decay (estimated experimental VmaxCa,decay 0.3 F340/ $380 / \mathrm{s}$ ) we got $1.91 / \mathrm{s}$ vs $4.51 / \mathrm{s}$, respectively experimental [11] and simulated. The last comparison regards the reduced VmaxCa,upstroke value after RyR application: in [11] an experimental value of $70 \%$ was reported, while our model simulated $78 \%$.

\section{Drug simulations}

Finally, we performed a preliminar test of the qualitative reproduction of the main effects on AP of well-established channel blockers. E4031 is known to prolong cardiac AP through $\mathrm{I}_{\mathrm{Kr}}$ selective blockade. We tested the effect of E4031 on a single spontaneously beating cluster of hESC-CMs at Early stage and observed a progressive decrease of the pacing frequency, a depolarization of MDP and an increase of APD involving all phases of repolarization (Figure 6A, left). These effects were fast on our experimental system and after $60 \mathrm{~s}$ from drug application the cluster showed a complete stop of its spontaneous electrical activity and beating [6]. To simulate this effect in our model, $\mathrm{G}_{\mathrm{Kr}}$ was decreased by $50 \%$ of its Early value and this resulted in AP prolongation (Figure $6 \mathrm{~A}$ right). In fact the $\mathrm{AP}$ lengthening measured at different values of repolarization were $12 \%\left(\mathrm{APD}_{30}\right), 18 \%$ $\left(\mathrm{APD}_{50}\right), 47 \%\left(\mathrm{APD}_{70}\right)$ and $110 \%\left(\mathrm{APD}_{90}\right)$. In the simulation MDP was also depolarized by $4 \%$, in accordance with a weaker contribution of repolarizing current, and frequency was reduced by $27 \%$. In our model a decrease of $\mathrm{I}_{\mathrm{Kr}}$ current larger than $50 \%$ produced a block of spontaneous beating, similarly to what observed experimentally [6].

In a single cluster of hESC-CMs at the Late stage, application of E4031 produced a fast depolarization of MDP and a remarkable increase in spontaneous rate with characteristic small amplitude oscillations of membrane potential (Figure 6B, left). At this stage, simulation was obtained by $60 \%$ reduction of $\mathrm{G}_{\mathrm{Kr}}$ that resulted in $\mathrm{AP}$ modifications qualitatively similar, even if smaller, to those observed experimentally. In particular, rate was increased by $97 \%, \mathrm{APD}_{70}$ by $19 \%, \mathrm{APD}_{90}$ by $65 \%$, MDP was depolarized by $17 \%$ (Figure $6 \mathrm{~B}$, right).

At millimolar concentration nickel is well known to largely block $\mathrm{I}_{\mathrm{NaCa}}$ and $\mathrm{I}_{\mathrm{CaT}}$. Furthermore, it has also been reported to block at a very high extent $I_{K r}$ in sinoatrial node cells [40]. All these currents are involved in different phases of spontaneous beating generation and AP. In the Early stage, application of nickel produced a marked MDP depolarization, a sustained APA reduction of and an increase of spontaneous rate, which lasted unaltered over time (Figure 6C, left). Conversely, at the Late stage, nickel first slowed down and then blocked completely electrical activity (Figure 6D, left). At both stages, simulations were performed reducing $\mathrm{I}_{\mathrm{CaT}}$ and $\mathrm{I}_{\mathrm{Kr}}$ by $90 \%$ and $\mathrm{I}_{\mathrm{NaCa}}$ by $75 \%$ of their initial values. The effects on APA, MDP and beating rate detected at the Early stage were well reproduced (Figure 6C, right). Blockade of spontaneous activity observed at the Late stage was also clearly mimicked in our model (Figure 6D, right).

\section{Discussion}

The major aim of this work was to develop a mathematical model able to reproduce the basal electrophysiological properties of hESC-CMs and the modifications induced 

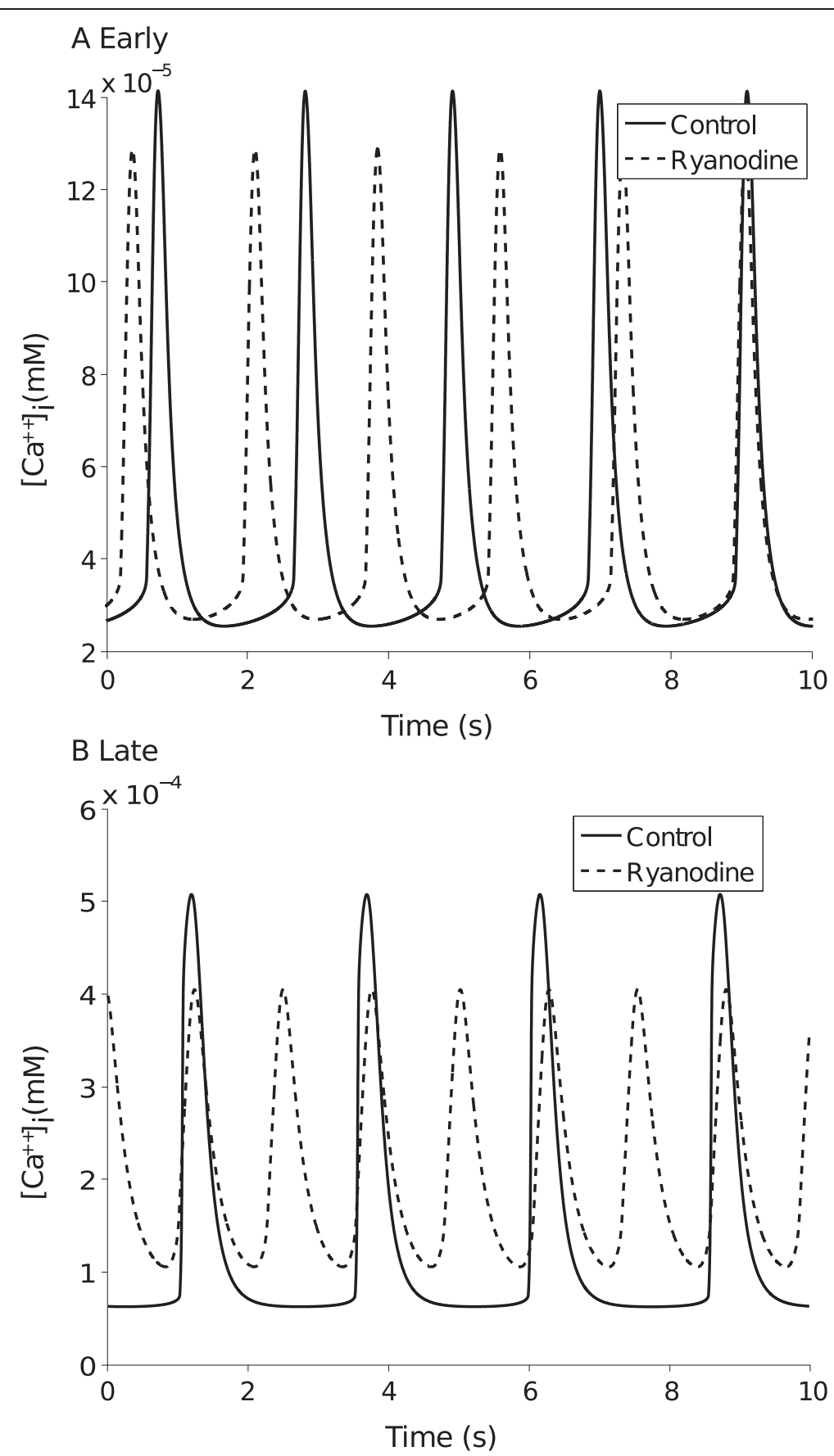

Figure $\mathbf{5}$ Effects of Ryanodine. Simulation of the reduction of calcium transient amplitude under the effect of Ryanodine at Early (A) and Late (B) stages

by in vitro maturation. This approach, has been applied for the first time to hESC-CMs and the model represents the first computational tool for studying the fundamental physiology of hESC-CMs, in particular those derived from the $\mathrm{H} 1$ cell line. Moreover, introducing the contribution of fibroblasts we approached the simulation of the properties of beating intact EBs, which represent the elementary functional unit able to promote electrophysiological maturation of hESC-CMs and therefore suitable for screening ion channel blockers and assessing the cardiac safety of drugs. 


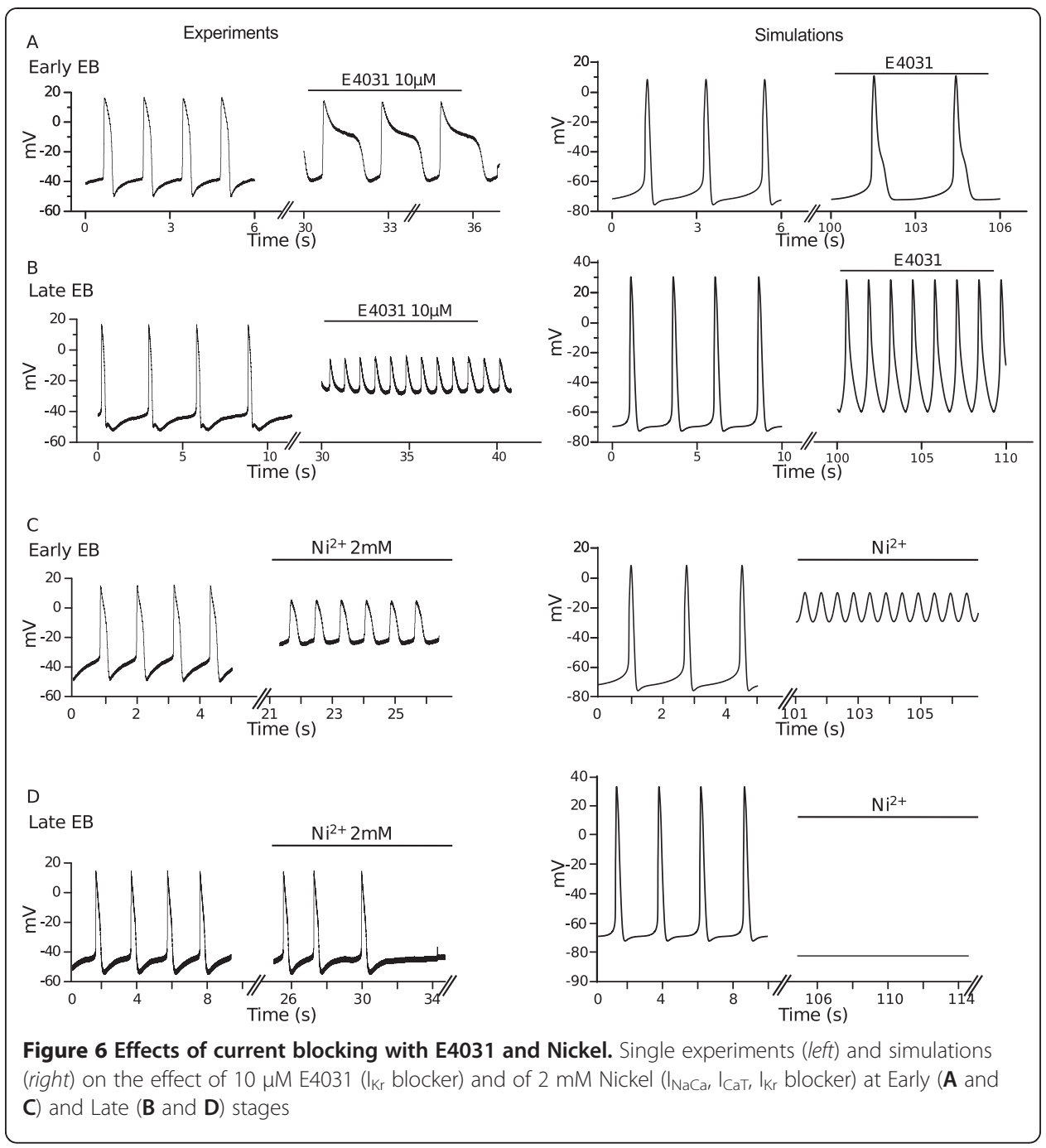

We reached the goal of reproducing the spontaneous AP profile of hESC-CMs, strongly focusing on the modifications occurring during the transition of intact EBs from the Early to the Late developmental stage. Specifically, we reproduced key modifications documented experimentally on intact EBs by multicellular recordings, including the decrease of spontaneous AP frequency in association with a reduced DDR, meaning that the automaticity was slowed down during simulated maturation, similarly to experimental observations. The maturation-related increase of APD was also satisfactorily mimicked by our model, thus reflecting the modifications identified for many ionic currents occurring during in vitro maturation. Of note, we chose this specific electrophysiological approach on intact EBs due to several advantages, including the preservation of tissue architecture that allows the detection of single cell transmembrane voltage resulting also from the contribution of neighbouring cells. The latter, beside non myocytic cells, may be represented by CMs with similar or different phenotypes, with a relative composition of different phenotypes depending mainly from the developmental stage under evaluation. In fact Early hESC-CMs have a rather homogeneous phenotype (mostly sinus nodal like) that progresses into different phenotypes 
in the Late phase (atrial, ventricular and sinus nodal). Therefore, our experimental and simulation data readily reflect the degree of phenotype dishomogeneity in most of action potential parameters, resulting from the contribution of individual CMs at different stages (throughout the developmental process) and the fate (ventricular, atrial or nodal). To further confirm this statement, the median measurements of action potential duration at different percentage of repolarization have a lower interquartile range in the Early phase compared to the Late (see Table 2).

Based on the integration into our model of original and literature data on different ionic currents, some considerations can be drawn on their role in the hESC-CM development.

$\mathrm{I}_{\text {to }}$ is known to play a key role during the early repolarization phase leading to the notched shape and plateau phase present in human adult ventricular and atrial cells [41]. In our experimental conditions we found that $\mathrm{I}_{\text {to }}$ density increased from the Early to the Late phase. This result is in line with our previous data demonstrating a functional and molecular up-regulation of $\mathrm{I}_{\text {to }}$ during $\mathrm{hESC}$-CMs maturation. It further confirms that this channel is a fundamental marker of functional $\mathrm{CM}$ maturation among mammalians [6]. These modifications were favourably integrated in our model, thus demonstrating their positive contribution to its final formulation. However, our measurements of $I_{\text {to }}$ showed substantial current density also for negative potentials. For this reason $I_{\text {to }}$ half-maximal activation was shifted from 20 to $-5 \mathrm{mV}$ (Figure 1D) whereas the steepness of the model curve was kept slightly greater than the experimental one, as already done and discussed in the adult model [16].

A different set of original data integrated in our model is related to $\mathrm{I}_{\mathrm{f}}$. It is an inward current involved in the generation of spontaneous electrical activity, identified and characterized in our previous study on H1-hESC-CMs [6]. In the present study we further characterized this current identifying its functional relevance over an extended period of time. We calculated maximal conductance for the Early stage and extrapolated its value at the Late one on the basis of a cumulative reduction of HCN total transcript. Although functional properties of currents do not uniquely depend on the amount of channel transcript/s, we hypothesised that $\mathrm{I}_{\mathrm{f}}$ density is likely to decrease during $\mathrm{hESC}$ maturation on the basis of different experimental evidences. First, the rate of spontaneous beating and the slope of the diastolic depolarization decrease with maturation (Table 1); secondly, $\mathrm{I}_{\mathrm{f}}$ downregulation is a well established marker of functional maturation of native CMs $[42,43]$. These observations led us to integrate in our model a $I_{f}$ contribution declining over maturation time. As observed for $I_{t o}$, this implementation had a positive effect on the model mimicking properties. As shown in Figure 3, modulation of $\mathrm{I}_{\mathrm{f}}$ mainly affects in the model the rate of spontaneous beating and the DDR at both stages but especially at the Early one. The Late stage represented a scenario characterized by a smaller $\mathrm{I}_{\mathrm{f}}$ and which evolves towards cells with no automaticity, so the $20 \%$ reduction of $\mathrm{RaI}_{\mathrm{f}}$ led to no spontaneous activity.

Experimental evidence documents the occurrence of developmental changes of $\mathrm{I}_{\mathrm{NaCa}}$ in different animal models, with maximal current density lowering throughout maturation [24]. In humans, $\mathrm{I}_{\mathrm{NaCa}}$ expression peaks at mid-gestation, overcoming that of the adult heart [44]. In hESC-CMs, [11] reported that $\mathrm{I}_{\mathrm{NaCa}}$ expression in the Early phase is higher with respect to that found in human fetal and adult ventricular CMs. This evidence is in line with our experimental results (see Figure 1F), showing larger current density both in $\mathrm{Ca}^{2+}$ outward and inward modes, at the Early stage with respect to the 
Late one. By contrast, a recent study [45] performed on a similar model led to opposite results, i.e. maximal current occurring in the Late stage. The explanation for such a difference is not obvious; diverse developmental window and/or cell phenotypes (ventricular and atrial vs ventricular) may account for these discrepancies. Model-based analysis showed that at both stages $\mathrm{I}_{\mathrm{NaCa}}$ (Figure 3) modulation affects basically all the AP features (tests with $\mathrm{RaI}_{\mathrm{NaCa}}-20 \%$ ) and the occurrence of spontaneous beating (tests with $\left.\mathrm{RaI}_{\mathrm{NaCa}}+20 \%\right)$.

Other relevant maturation-related current modifications introduced in our model are consistent with previous observations in rodent ESC-CMs. In particular $\mathrm{I}_{\mathrm{Kr}}$ decrease and $\mathrm{I}_{\mathrm{Na}}$ increase confirmed to be important to achieve AP changes such as AP prolongation and increase in Vmax observed with hESC-CM development. As expected $I_{\mathrm{Na}}$ had the strongest influence on Vmax while $\mathrm{I}_{\mathrm{Kr}}$ had a considerable effect on the APD, especially in the latest phases of the repolarization (see Figure 3).

The sensitivity analysis summarized in Figure 3 helps in assessing the maturationrelated effects on the spontaneous contractile activity of hESC-CMs, in particular showing that at the Late stage it is more sensitive to current variations that at the Early stage. At the Early stage the reduction of the depolarizing $\mathrm{I}_{\mathrm{CaL}}$ (necessary for the upstroke) and the increment of $\mathrm{I}_{\mathrm{NaCa}}$ (inward current during the late-repolarization) caused the spontaneous beating stop. In addition to the reduced $\mathrm{I}_{\mathrm{CaL}}$ and increased $\mathrm{I}_{\mathrm{NaCa}}$ tests, the Late stage showed no spontaneous beating also for increments of the main repolarizing currents $\mathrm{I}_{\mathrm{Kr}}, \mathrm{I}_{\mathrm{K} 1}, \mathrm{I}_{\mathrm{Ks}}$ and $\mathrm{I}_{\mathrm{NaK}}$, thus supporting the hypothesis of a weakening of the spontaneous depolarization during maturation. Moreover, also the effect of the $20 \% \mathrm{I}_{\mathrm{f}}$ reduction at the Late stage is indicative of this mechanism since $\mathrm{I}_{\mathrm{f}}$ was already reduced during the transition from the Early to the Late stage.

We also tested coupling of fibroblasts with the hESC-CM model. Our hypothesis was that such approach could improve the quality of simulated APs that are generated by a complex system comprising CMs embedded in a cluster of different cells, such as fibroblasts. Indeed, one specific AP feature predicted by our model (MDP) differed substantially with respect to the experimental data. At both developmental stages, effects of coupling were small and consisted of MDP depolarization and increase of DDR and frequency. These effects can be explained by observing that during diastole fibroblast membrane potential is less negative with respect to that of CMs, causing a small depolarizing current flowing into CMs. Although limited, these modifications collectively move our simulation towards the experimental measurements, therefore improving the mimicking potential of our model. On this basis, it would be interesting to explore the possibility to enlarge the cell network by including different cell phenotypes (e.g. endothelial cells) possibly present in vivo. Globally, our results are in line with similar studies [37], where coupling of the TenTusscher model to fibroblasts led to a slightly depolarized resting potential, reduced APA and to the electrotonic modulation of the fibroblast potential by the coupled CM.

Recently, increasing attention has been focused on the development and maturation of the SR activity in hESC-CMs. Accumulated evidence points to a significant activity of $\mathrm{Ca}^{2+}$ release from SR [11,12], even if less organized and regulated than in mature CMs. In fact, while in the Early phase H1-hESC-CMs express SERCA2a, other proteins such as calsequestrin, triadin and junctin are almost absent [46]. Moreover, at 40-50 days of differentiation, T-tubules remain undetected on the sarcolemma, suggesting a 
topological environment different from mature, where $\mathrm{Ca}^{2+}$ influx through $\mathrm{Ca}^{2+}$ channels in the T-tubule is tightly associated with sarcoplasmic RyR channels [10]. Overexpression of calsequestrin in H1-hESC-CMs failed to induce the growth of T-tubules even though SR load and $\mathrm{Ca}^{2+}$ transient amplitude became more similar to those of mature CMs [47]. Simulations of $\mathrm{Ca}^{2+}$ transients using our model led to results fully consistent with the experimental data reported above. In fact, upon blockade of $\mathrm{Ca}^{2+}$ release from SR we found a decreased $\mathrm{Ca}^{2+}$ transient amplitude by $12 \%$ in the Early, and by $33 \%$ in the Late phase, similarly to the results reported experimentally $[11,12]$. Overall, these results indicate that in the Early stage $\mathrm{Ca}^{2+}$ cycling is mainly governed by sarcolemmal fluxes, while upon maturation $\mathrm{Ca}^{2+}$ release from SR increases its contribution moving toward a functional integration with sarcolemma to generate rhythmic activity. This evidence is in line with recent data obtained in late-stage mouse ESC [46] and further extends the predictive potential of our model to intracellular $\mathrm{Ca}^{2+}$ handling processes. Simulated block of $\mathrm{Ca}^{2+}$ release also increased the oscillation frequency (see Figure 5); we are not aware of experimental reports on this specific aspect in hESC-CMs which, on the other hand, seems in contrast with the effect of RyR knock out in ESC-CMs [48]. However, in the same conditions, a consistent increase in the frequency of AP-induced $\mathrm{Ca}^{2+}$ transients is apparent also in [12] (Figure 6), thus suggesting that further investigation supported also by model based analysis might provide mechanistic insights on this issue.

In our model, simulations of channel blockers were aimed to test, as a proof of concept, a qualitative reproduction of the main experimentally AP modifications observed in preliminar experiments. In the case of $\mathrm{I}_{K v}$ a reduction in the maximal conductance simulated the application of E4031. This operation altered AP shapes quite similarly to what observed in the experiment, despite the fact that simulated AP prolongation was far less pronounced at the Early stage while at the Late stage MDP was more negative with respect to the experimental trace. Importantly, our model replicates the effect of E4031 on the frequency of spontaneous beating, which decreases in the Early stage and markedly increases in the Late one.

Our experiments using $2 \mathrm{mM}$ nickel were simulated by a relevant blockade of $\mathrm{I}_{\mathrm{NaCa}}$, $\mathrm{I}_{\mathrm{CaT}}$ and $\mathrm{I}_{\mathrm{Kr}}$ in the model, in accordance with the lack of selectivity of nickel at this concentration and the high levels of block reported for these currents. At the Early stage simulations and experimental recording similarly show a residual electrical activity slightly different in frequency and amplitude (see Figure 6C); nonetheless, both results suggest that residual currents are sufficient to drive a repetitive potential oscillation of small amplitude occurring at depolarized potentials. For the Late stage experimental traces and simulations show a complete block of spontaneous activity (see Figure 6D) occurring at negative potential values, opening the hypothesis that in this phase, where other depolarizing currents such as $\mathrm{I}_{\mathrm{f}}$ are downregulated, $\mathrm{I}_{\mathrm{NaCa}}$ plays a key role in sustaining the spontaneous activity. Our results are consistent with those of similar experiments [45] performed with $5 \mathrm{mM}$ nickel, a concentration expected to exert a higher level of channel blockade. In fact, with this higher nickel concentration no $\mathrm{Ca}^{2+}$ transients due to spontaneous activity were recorded at any developmental stage.

\section{Limitations}

The main limitations of our work are related to i) the shortage of data and ii) the variability of phenotypes. We built an AP model for human embryonic stem cells derived 
cardiomyocytes. However, many data to build the model are taken from published experimental work on different animal species. The crossbreeding process of data from human and animal CMs represented a compulsory choice for our model, since some current properties expressed in the adult ventricular cells were unknown or not sufficiently characterized in hESC-CMs. A more accurate numerical model of "human" embryonic stem cells derived cardiomyocytes would require further experimental investigations. This should be considered as a first step in the effort of mathematically describing the ESC-CM electrophysiology aimed at capturing the qualitative mechanisms.

The choice of a specific human adult ventricular AP model as the basis for the hESC-CM model could be perceived as a limitation of the present work. We chose as the "starting point" for the development of our model a modified version of the TenTusscher model [15], in which $\mathrm{I}_{\mathrm{Kr}} \mathrm{I}_{\mathrm{Ks}}$ and $\mathrm{I}_{\mathrm{CaL}}$ were changed with respect to their original formulation. From this starting point, in order to reproduce developmental changes in each current we modulated (through the $\mathrm{RaI}_{\mathrm{xx}}$ ratios) the current maximal conductances. But at the same time the kinetic of several currents were changed based on data from ESC-CMs: $\mathrm{I}_{\mathrm{Na}}, \mathrm{I}_{\mathrm{CaL}}, \mathrm{I}_{\mathrm{to}}, \mathrm{I}_{\mathrm{K} 1}, \mathrm{I}_{\mathrm{NaCa}}$. Moreover, two relevant membrane currents that were not present in the adult ventricular model $\left(\mathrm{I}_{\mathrm{CaT}}\right.$ and $\left.\mathrm{I}_{\mathrm{f}}\right)$ were incorporated in our model. All these modifications reduced the actual impact on the final results of the initial choice of the starting point. A sensitivity analysis with respect to the choice of the parent model was far beyond the scope of the present work. It is also worth noting that the modification of the Ten Tusscher model allowed the correct prediction of APD shortening at higher $\left[\mathrm{Ca}^{2+}\right]_{\mathrm{o}}$ [15]. All the more recent models (e.g. [49]) show unrealistic APD prolongation upon increase of extracellular calcium. This aspect is particularly relevant for our study, in which we had to reproduce intracellular AP recordings obtained with $2.7 \mathrm{mM} \mathrm{Ca}^{2+}$ in the external solution [50].

The difference in MDP between experiments and simulations is a limitation, possibly related to an incomplete description of the complex interconnection within the EBs. For example, in simulating AP recorded from EBs, only CM to fibroblast coupling has been considered. Other variables, such as $\mathrm{CM}$ to $\mathrm{CM}$ gap junctions likely contribute to the AP properties of EBs. However, such a term would dramatically complicate the system of differential equations and goes beyond the scope of the present work.

\section{Conclusions}

In conclusion, this study provides the first modelling tool able to simulate the membrane AP, the associated intracellular $\mathrm{Ca}^{2+}$ handling properties and the modification occurring over the maturation process of hESC-CMs. The simulation of the transition from Early to Late developmental stage involved: increasing $\mathrm{I}_{\text {to }}$ density, declining $I_{f}$ contribution, decreasing $I_{\mathrm{NaCa}}$ current density, $\mathrm{I}_{\mathrm{Kr}}$ decrease and $\mathrm{I}_{\mathrm{Na}}$ increase. Moreover, an increasing contribution to $\mathrm{Ca}^{2+}$ cycling of the $\mathrm{Ca}^{2+}$ release from SR was pointed out.

We expect to overcome inherent limitations present in the model by further experimental investigations exploring unknown properties of basic physiology of hESCCMs, possibly including different stem cell lines. Also, the combined use of novel pharmacological/simulated challenges will be useful to implement and validate the predictive potential of the model. Finally, novel challenges come from studies 
(including drug testing) in CMs from induced pluripotent stem cells carrying genetic mutations [51,52]; the development of disease-specific cell lines for genetic cardiac disorders prompts toward the refinement of this mathematical modelling to address future directions in this field.

\section{Additional file}

Additional file 1: Supplementary Methods: Mathematical Modelling of the Action Potential of Human Embryonic Stem Cell derived Cardiomyocytes. Additional figure S1: $\mathrm{I}_{\mathrm{ks}}$ tail current. Additional figure S2: APD rate-dependence $[53,54]$.

\section{Abbreviations}

AP: Action potential; APA: Action potential amplitude; APD: Action potential duration; APD xx: Action potential duration at XX\% of repolarization; $C_{m}$ : Membrance capacitance; CM: Cardiomyocyte; DDR: Diastolic depolarization rate; EB: Embryoid body; F: Frequency of spontaneous beating; $G_{x x}$ : $I_{x x}$ current conductance; hESC: Human embryonic stem

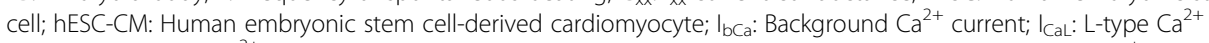
current; $I_{\mathrm{CaT}}$ : T-type $\mathrm{Ca}^{2+}$ current; $\mathrm{I}_{\mathrm{f}}$ : Hyperpolarization activated funny current; $\mathrm{I}_{\mathrm{K}}$ : Rapid delayed rectifying $\mathrm{K}^{+}$current; $I_{\mathrm{Ks}}$ : Slow delayed rectifying $\mathrm{K}^{+}$current; $I_{\mathrm{K} 1}$ : Inward rectifying $\mathrm{K}^{+}$current; $I_{\text {leak: }}$ Leakage $\mathrm{Ca}^{2+}$ current; $I_{\text {maxxx: }} I_{\mathrm{xx}}$ maximal current; $I_{\mathrm{Na}}: \mathrm{Na}^{+}$current; $I_{\mathrm{NaCa}}: \mathrm{Na}^{+} / \mathrm{Ca}^{2+}$ exchanger current; $\mathrm{I}_{\mathrm{NaK}}: \mathrm{Na}^{+} / \mathrm{K}^{+}$pump; $\mathrm{I}_{\mathrm{pCa}}$ : Sarcolemmal $\mathrm{Ca}^{2+}$ pump; $\mathrm{I}_{\text {rel: }}$ Release $\mathrm{Ca}^{2+}$ current; $\mathrm{I}_{\text {to: }}$ Transient outward $\mathrm{K}^{+}$current; I $\mathrm{I}_{\mathrm{p}}$ : Uptake $\mathrm{Ca}^{2+}$ current; MDP: Maximum diastolic potential; $\mathrm{Ra}_{\mid \mathrm{xx}}$ : Variable fraction of the $\mathrm{I}_{\mathrm{xx}}$ current maximal conductance in the adult model; SR: Sarcoplasmic reticulum; Vmax: Maximal upstroke velocity of the membrane potential; VmaxCa,upstroke: Maximal upstroke velocity of the Ca ${ }^{2+}$ transient; $V$ maxCa,decay: Maximal decay velocity of the $\mathrm{Ca}^{2+}$ transient.

\section{Competing interests}

The authors declare that they have no competing interests.

\section{Authors' contributions}

MP: conception and design, data analysis and interpretation, manuscript writing, final approval of manuscript. LS: provision of study material, collection and assembly of data, data analysis and interpretation, manuscript writing, final approval of manuscript. MDL: provision of study material, collection and assembly of data, manuscript revision, final approval of manuscript. MJ: provision of study material, manuscript revision, final approval of manuscript. AM: provision of study material, manuscript revision, final approval of manuscript. EC: conception and design, collection and assembly of data, data analysis and interpretation, final approval of manuscript. SS: conception and design, data analysis and interpretation, manuscript writing, final approval of manuscript. All authors read and approved the final manuscript.

\section{Acknowledgments}

This work was supported by grants from Ministero dell'Istruzione, dell'Universita' e della Ricerca, Programmi di Ricerca di Interesse Nazionale (2008838SN9 to A.M.) and from Ente Cassa di Risparmio di Firenze (to E.C.).

\section{Author details}

${ }^{1}$ Biomedical Engineering Laboratory - D.E.I.S, University of Bologna, Via Venezia 52, Cesena 47521, Italy. ${ }^{2}$ Center of Molecular Medicine (C.I.M.M.B.A.), University of Firenze, Viale Pieraccini 6, Florence 50139, Italy. ${ }^{3}$ Department of Pathology and Immunology, University of Geneva, Rue Michel-Servet 1, Geneva 4 1211, Switzerland.

Received: 13 February 2012 Accepted: 27 June 2012

Published: 28 August 2012

\section{References}

1. Thomson JA: Embryonic stem cell lines derived from human blastocysts. Science 1998, 282:1145-1147.

2. Rao TP, Kühl M: An updated overview on Wnt signaling pathways: a prelude for more. Circ Res 2010, 106:1798-1806.

3. Phillips BW, Crook JM: Pluripotent human stem cells: a novel tool in drug discovery. BioDrugs 2010, 24:99-108.

4. Bel A, Planat-Bernard V, Saito A, Bonnevie L, Bellamy V, Sabbah L, Bellabas L, Brinon B, Vanneaux V, Pradeau P, Peyrard S, Larghero J, Pouly J, Binder P, Garcia S, Shimizu T, Sawa Y, Okano T, Bruneval P, Desnos M, Hagège AA, Casteilla L, Pucéat M, Menasché P: Composite cell sheets: a further step toward safe and effective myocardial regeneration by cardiac progenitors derived from embryonic stem cells. Circulation 2010, 122:S118-S123.

5. Pekkanen-Mattila M, Kerkelä E, Tanskanen JMA, Pietilä M, Pelto-Huikko M, Hyttinen J, Skottman H, Suuronen R, Aalto-Setälä K: Substantial variation in the cardiac differentiation of human embryonic stem cell lines derived and propagated under the same conditions-a comparison of multiple cell lines. Ann Med 2009, 41:360-370.

6. Sartiani L, Bettiol E, Stillitano F, Mugelli A, Cerbai E, Jaconi ME: Developmental changes in cardiomyocytes differentiated from human embryonic stem cells: a molecular and electrophysiological approach. Stem Cells 2007, 25(5):1136-1144.

7. Zeevi-Levin N, Itskovitz-Eldor J, Binah O: Functional properties of human embryonic stem cell-derived cardiomyocytes. Crit Rev Eukaryot Gene Expr 2010, 20:51-59. 
8. Asai Y, Tada M, Otsuji TG, Nakatsuji N: Combination of functional cardiomyocytes derived from human stem cells and a highly-efficient microelectrode array system: an ideal hybrid model assay for drug development. Curr Stem Cell Res Ther 2010, 5:227-232.

9. Kim C, Majdi M, Xia P, Wei KA, Talantova M, Spiering S, Nelson B, Mercola M, Chen H-SV: Non-cardiomyocytes influence the electrophysiological maturation of human embryonic stem cell-derived cardiomyocytes during differentiation. Stem Cells Dev 2010, 19:783-795.

10. Lieu DK, Liu J, Siu C-W, Mcnerney GP, Tse H-F, Abu-Khalil A, Huser T, Li RA: Absence of transverse tubules contributes to non-uniform ca2 + wavefronts in mouse and human embryonic stem cell-derived cardiomyocytes. Stem Cells Dev 2009, 18:1493-1500.

11. Liu J, Fu JD, Siu CW, Li RA: Functional sarcoplasmic reticulum for calcium handling of human embryonic stem cell-derived cardiomyocytes: insights for driven maturation. Stem Cells 2007, 25:3038-3044.

12. Satin J, Itzhaki I, Rapoport S, Schroder EA, Izu L, Arbel G, Beyar R, Balke CW, Schiller J, Gepstein L: Calcium handling in human embryonic stem cell-derived cardiomyocytes. Stem Cells 2008, 26:1961-1972.

13. Itzhaki I, Schiller J, Beyar R, Satin J, Gepstein L: Calcium handling in embryonic stem cell-derived cardiac myocytes: of mice and men. Ann N Y Acad Sci 2006, 1080:207-215.

14. Noble D: Computational models of the heart and their use in assessing the actions of drugs. J Pharmacol Sci 2008, 107:107-117.

15. Grandi E, Pasqualini FS, Pes C, Corsi C, Zaza A, Severi S: Theoretical investigation of action potential duration dependence on extracellular Ca2+ in human cardiomyocytes. J Mol Cell Cardiol 2009, 46(3):332-342.

16. ten Tusscher KHWJ, Noble D, Noble PJ, Panfilov AV: A model for human ventricular tissue. Am J Physiol Heart Circ Physiol 2004, 286(4):H1573-H1589.

17. Hodgkin A, Huxley A: A quantitative description of membrane current and its application to conduction and excitation in nerve. J Physiol (Lond) 1952, 117:500-544.

18. Ferron L, Capuano V, Deroubaix E, Coulombe A, Renaud J-F: Functional and molecular characterization of a T-type $\mathrm{Ca}(2+)$ channel during fetal and postnatal rat heart development. J Mol Cell Cardiol 2002, 34:533-546.

19. Davies MP, An RH, Doevendans P, Kubalak S, Chien KR, Kass RS: Developmental changes in ionic channel activity in the embryonic murine heart. Circ Res 1996, 78:15-25.

20. Kato Y, Masumiya H, Agata N, Tanaka H, Shigenobu K: Developmental changes in action potential and membrane currents in fetal, neonatal and adult guinea-pig ventricular myocytes. J Mol Cell Cardiol 1996, 28:1515-1522.

21. Liu W, Yasui K, Opthof T, Ishiki R, Lee JK, Kamiya K, Yokota M, Kodama I: Developmental changes of Ca(2+) handling in mouse ventricular cells from early embryo to adulthood. Life Sci 2002, 71:1279-1292.

22. Masuda $\mathrm{H}$, Sperelakis N: Inwardly rectifying potassium current in rat fetal and neonatal ventricular cardiomyocytes. Am J Physiol 1993, 265:H1107-H1111.

23. Satin J, Kehat I, Caspi O, Huber I, Arbel G, Itzhaki I, Magyar J, Schroder EA, Perlman I, Gepstein L: Mechanism of spontaneous excitability in human embryonic stem cell derived cardiomyocytes. J Physiol (Lond) 2004, 559:479-496.

24. Itoh H, Naito Y, Tomita M: Simulation of developmental changes in action potentials with ventricular cell models. Syst Synth Biol 2007, 1:11-23.

25. Ono K, lijima T: Cardiac T-type Ca(2+) channels in the heart. J Mol Cell Cardiol 2010, 48:65-70.

26. Yanagi K, Takano M, Narazaki G, Uosaki H, Hoshino T, Ishii T, Misaki T, Yamashita JK: Hyperpolarization-activated cyclic nucleotide-gated channels and T-type calcium channels confer automaticity of embryonic stem cell-derived cardiomyocytes. Stem Cells 2007, 25:2712-2719.

27. Maltsev V, Lakatta EG: Synergism of coupled subsarcolemmal Ca2+ clocks and sarcolemmal voltage clocks confers robust and flexible pacemaker function in a novel pacemaker cell model. Am J Physiol Heart Circ Physiol 2009, 296:H594-H615.

28. Courtemanche M, Ramirez RJ, Nattel S: Ionic mechanisms underlying human atrial action potential properties: insights from a mathematical model. Am J Physiol 1998, 275:H301-H321.

29. Spence SG, Vetter C, Hoe CM: Effects of the class III antiarrhythmic, dofetilide $(U K-68,798)$ on the heart rate of midgestation rat embryos, in vitro. Teratology 1994, 49:282-292.

30. Chun KR, Koenen M, Katus HA, Zehelein J: Expression of the IKr components KCNH2 (rERG) and KCNE2 (rMiRP1) during late rat heart development. Exp Mol Med 2004, 36:367-371.

31. Wang L, Feng ZP, Kondo CS, Sheldon RS, Duff HJ: Developmental changes in the delayed rectifier $\mathrm{K}+$ channels in mouse heart. Circ Res 1996, 79:79-85.

32. Wang K, Terrenoire C, Sampson KJ, lyer V, Osteen JD, Lu J, Keller G, Kotton DN, Kass RS: Biophysical properties of slow potassium channels in human embryonic stem cell derived cardiomyocytes implicate subunit stoichiometry. J Physiol 2011, 589(Pt 24):6093-6104.

33. Difrancesco D: A new interpretation of the pace-maker current in calf Purkinje fibres. J Physiol (Lond) 1981, 314:359-376.

34. Otsu K, Kuruma A, Yanagida E, Shoji S, Inoue T, Hirayama Y, Uematsu H, Hara Y, Kawano S: Na+/K+ ATPase and its functional coupling with $\mathrm{Na}+/ \mathrm{Ca} 2+$ exchanger in mouse embryonic stem cells during differentiation into cardiomyocytes. Cell Calcium 2005, 37:137-151.

35. Romero L, Pueyo E, Fink M, Rodriguez B: Impact of ionic current variability on human ventricular cellular electrophysiology. AJP: Heart and Circulatory Physiology 2009, 297:H1436-H1445.

36. Romero L, Carbonell B, Trenor B, Rodríguez B, Saiz J, Ferrero JM: Systematic characterization of the ionic basis of rabbit cellular electrophysiology using two ventricular models. Prog Biophys Mol Biol 2011, 107:60-73.

37. MacCannell KA, Bazzazi H, Chilton L, Shibukawa Y, Clark RB, Giles WR: A mathematical model of electrotonic interactions between ventricular myocytes and fibroblasts. Biophys J 2007, 92:4121-4132.

38. Kohl P, Kamkin AG, Kiseleva IS, Noble D: Mechanosensitive fibroblasts in the sino-atrial node region of rat heart: interaction with cardiomyocytes and possible role. Exp Physiol 1994, 79:943-956.

39. Jacquemet $\mathrm{V}$, Henriquez CS: Modelling cardiac fibroblasts: interactions with myocytes and their impact on impulse propagation. Europace 2007, 9(Suppl. 6):vi29-vi37. 
40. Song DK, Earm YE, Ho WK: Blockade of the delayed rectifier $\mathrm{K}+$ currents, IKr, in rabbit sinoatrial node cells by external divalent cations. Pflugers Arch 1999, 438:147-153.

41. Oudit GY, Kassiri Z, Sah R, Ramirez RJ, Zobel C, Backx PH: The molecular physiology of the cardiac transient outward potassium current (I(to)) in normal and diseased myocardium. J Mol Cell Cardiol 2001, 33:851-872.

42. Cerbai E, Pino R, Sartiani L, Mugelli A: Influence of postnatal-development on I(f) occurrence and properties in neonatal rat ventricular myocytes. Cardiovasc Res 1999, 42:416-423.

43. Yasui K, Liu W, Opthof T, Kada K, Lee JK, Kamiya K, Kodama I: I(f) current and spontaneous activity in mouse embryonic ventricular myocytes. Circ Res 2001, 88:536-542.

44. Qu Y, Ghatpande A, El-Sherif N, Boutjdir M: Gene expression of Na+/Ca2+ exchanger during development in human heart. Cardiovasc Res 2000, 45:866-873.

45. Fu J-D, Jiang P, Rushing S, Liu J, Chiamvimonvat N, Li RA: Na+/Ca2+ exchanger is a determinant of excitationcontraction coupling in human embryonic stem cell-derived ventricular cardiomyocytes. Stem Cells Dev 2010, 19:773-782.

46. Zahanich I, Sirenko SG, Maltseva LA, Tarasova YS, Spurgeon HA, Boheler KR, Stern MD, Lakatta EG, Maltsev VA: Rhythmic beating of stem cell-derived cardiac cells requires dynamic coupling of electrophysiology and $\mathrm{Ca}$ cycling. J Mol Cell Cardiol 2011, 50:66-76.

47. Liu J, Lieu DK, Siu CW, Fu J-D, Tse H-F, Li RA: Facilitated maturation of Ca2+ handling properties of human embryonic stem cell-derived cardiomyocytes by calsequestrin expression. Am J Physiol Cell Physio/ 2009, 297:C152-C159.

48. Yang H, Tweedie D, Wang S, Guia A, Vinogradova T, Bogdanov K, Allen PD, Stern MD, Lakatta EG, Boheler KR: The ryanodine receptor modulates the spontaneous beating rate of cardiomyocytes during development. Proc Natl Acad Sci USA 2002, 99:9225-9230.

49. O'hara T, Virág L, Varró A, Rudy Y, Mcculloch A: Simulation of the undiseased human cardiac ventricular action potential: model formulation and experimental validation. PLoS Comput Biol 2011, 7:e1002061.

50. Bettiol E, Sartiani L, Chicha L, Krause KH, Cerbai E, Jaconi ME: Fetal bovine serum enables cardiac differentiation of human embryonic stem cells. Differentiation; research in biological diversity 2007, 75:669-681.

51. Yazawa M, Hsueh B, Jia X, Pasca AM, Bernstein JA, Hallmayer J, Dolmetsch RE: Using induced pluripotent stem cells to investigate cardiac phenotypes in Timothy syndrome. Nature 2011, 471:230-234.

52. Matsa E, Rajamohan D, Dick E, Young L, Mellor I, Staniforth A, Denning C: Drug evaluation in cardiomyocytes derived from human induced pluripotent stem cells carrying a long QT syndrome type 2 mutation. Eur Heart J 2011, 32:952-962.

53. Sartiani L, Cerbai E, Lonardo G, DePaoli P, Tattoli M, Cagiano R, Carratù MR, Cuomo V, Mugelli A: Prenatal exposure to carbon monoxide affects postnatal cellular electrophysiological maturation of the rat heart: a potential substrate for arrhythmogenesis in infancy. Circulation 2004, 109(3):419-423.

54. Barbieri M, Varani K, Cerbai E, Guerra L, Li Q, Borea PA, Mugelli A: Electrophysiological basis for the enhanced cardiac arrhythmogenic effect of isoprenaline in aged spontaneously hypertensive rats. J Mol Cell Cardiol 1994, 26(7):849-860.

doi:10.1186/1475-925X-11-61

Cite this article as: Paci et al:: Mathematical modelling of the action potential of human embryonic stem cell derived cardiomyocytes. BioMedical Engineering OnLine 2012 11:61.

\section{Submit your next manuscript to BioMed Central and take full advantage of:}

- Convenient online submission

- Thorough peer review

- No space constraints or color figure charges

- Immediate publication on acceptance

- Inclusion in PubMed, CAS, Scopus and Google Scholar

- Research which is freely available for redistribution

Submit your manuscript at www.biomedcentral.com/submit 